\title{
Localizing Optic Disk using LBP, SIFT and ICA
}

\author{
Amanjot Kaur ${ }^{1}$ \\ Computer Science Department \\ Chandigarh Group of Colleges, \\ Gharuan, Mohali-140413, India
}

\author{
Rajdavinder Singh Boparai ${ }^{2}$ \\ Computer Science Department \\ Chandigarh Group of Colleges, \\ Gharuan, Mohali-140413, India
}

\begin{abstract}
Various eye diseases such as diabetic retinopathy and glaucoma are very chronic, they has to be detected in early stage, so that harmful effects of such diseases can be minimized, also biometrics authentication plays a crucial role in daily life activities. So retinal fundus photography is commonly used in above mentioned area of problems. Because of Time-consuming and resource -intensive process, degradation of such images takes place. This paper presents a novel method to automatically localize one such feature: the optic disk. The proposed method consists of various steps: in the first step, a circular region of interest is found by first isolating the brightest area in the image by means preprocessing, and in the second step, the Hough transform is used to detect the main circular feature (corresponding to the optical disk) within the positive horizontal gradient image within this region of interest and we done this feature extraction with the SIFT and LBP algorithm. Initial results on a database of fundus images show that the proposed method is effective and favorable in relation to comparable techniques. The whole simulation result takes place in the MATLAB environment.
\end{abstract}

\section{General Terms}

Optic Disk, SIFT

\section{Keywords}

Retinal imaging, Hough transform, biomedical imaging, optic disk, SIFT, LBP, circular Hough transform.

\section{INTRODUCTION}

Retina is the innermost layer of the eye which can be visualized using adequate apparatus such as fundus camera [1]. Commonly Large scale screening is done using Fundus Photography. Diseases like cataract, glaucoma are mainly found in diabetes patients that lead to low vision. OD detection is one of the key preprocessing component in many algorithms designed for the automatic extraction of retinal anatomical structures.

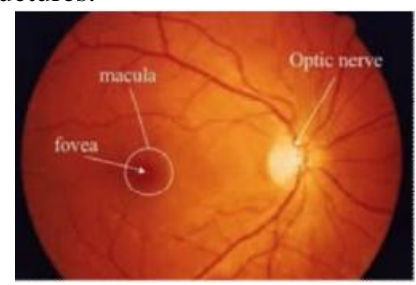

Fig. 1 Retinal Image

Above, Figure 1 shows a healthy retinal image including main retinal features i.e. optic nerve, blood vessels and macula. The shape, color and size of optic disc help in localization and detection.

The method proposed in this work will depend on SIFT, LBP, Circular Hough transform. The rest of paper is organized as in section II Literature survey will be described, In section III proposed technique is described, In section IV results will be discussed and Finally in Section IV conclusion and future scope will be discussed.

\section{RELATED WORK}

This section will include the literature survey of various methods that has been used for localization of optic disc.

Osareh [ $\underline{8}]$ proposed a method that uses the concept of template matching for the localization of the center of the optic disc. This algorithm consists of mainly two steps: in first step few images are used for template creation and in second step template matching is done on the basis of correlation between images. Maximum correlation value is considered as the centre point of the optic disc.

Youssif et al. [9] proposed the method of directional pattern of the retinal blood vessels for the localization of the center of the optic disc. Matching filter has been used to match the direction of blood vessels. After that, segmentation of retinal vessels is done using2D Gaussian matched filter. The recursion of this segmentation steps takes place to get the thinned and filter vessels, so that representation of the candidate optic disc center takes place. The Gaussian matched filter was resized in four different sizes, and the difference between the output of the matched filter and the vessels' directions was measured to get the optimal center point .

$\mathrm{Li}$ and Chutatape [10] presented a technique that in based on clustering method . In this firstly, candidate regions were first determined by clustering the brightest pixels in retinal images. This algorithm has some assumptions like there is no abnormality in the retina image. Feature extraction is done using PCA. Then,the minimum distance between the original retinal image and its projection onto disk space was located as the center of optic disc.

Rangayyan et al. $[\underline{11}, \underline{12}]$ proposed combination of two methods. In the first method, optic disc center was localized based on the property of the focal point of the blood vessels in retina image. Use of Gabor filters and detection of peaks are also done. In the second method, edge detection using the Sobel operators and detection of circles using the Hough transform were employed to localize optic disc and its center.

Aquino et al. [13] used two independent methodologies to detect optic disc in retina images. Finding the pixel that belongs to optic disc is done by using contrast analysis and structural filtering techniques. Then boundary segmentation is done by using mathematical morphology, edge detection techniques, and the circular Hough transform.

Siddalingaswamy and Gopalakrishna Prabhu [14] presented a technique for the localization and boundary detection of the optic disc. Iterative thresholding method and connected component analysis was utilised to localize the approximate 
center of the optic disc. Then, to find the exact boundary of the optic disc, Geometric model based on implicit active contour model was employed.

Foracchia et al. [15] presented a new technique for localizing the optic disc center in retinal images. The method uses the concept of preliminary detection of the main retinal vessels. This method estimates that all retinal vessels originate from the optic disc and their path follows a similar directional pattern in all images. A geometrical parametric model was proposed, where two of the model parameters are the coordinates of the optic disc, to describe the general direction of retinal vessels at any given position in the image.

Carmona et al. [16] used genetic algorithm method to obtain an ellipse approximating the optic disc in retinal images.

Initially a set of hypothesis points were obtained that exhibited geometric properties and intensity levels similar to the optic disc contour pixels. Then, a genetic algorithm (GA) has been utilised to find an ellipse containing the maximum number of hypothesis points in an offset of its perimeter, considering some constraints.

A number of other novel techniques can be found in the literature that used vessel segmentation results for optic disc localization [17-20].

Some methods are based on the Hough transform which is capable of finding geometric shapes. Therefore, the circular shape of optic disc was detected using Hough transform and other algorithms such as thresholding and morphological operations [21-25].

\section{PROPOSED METHOD}

This section discusses the proposed methodology for localizing optic disk.

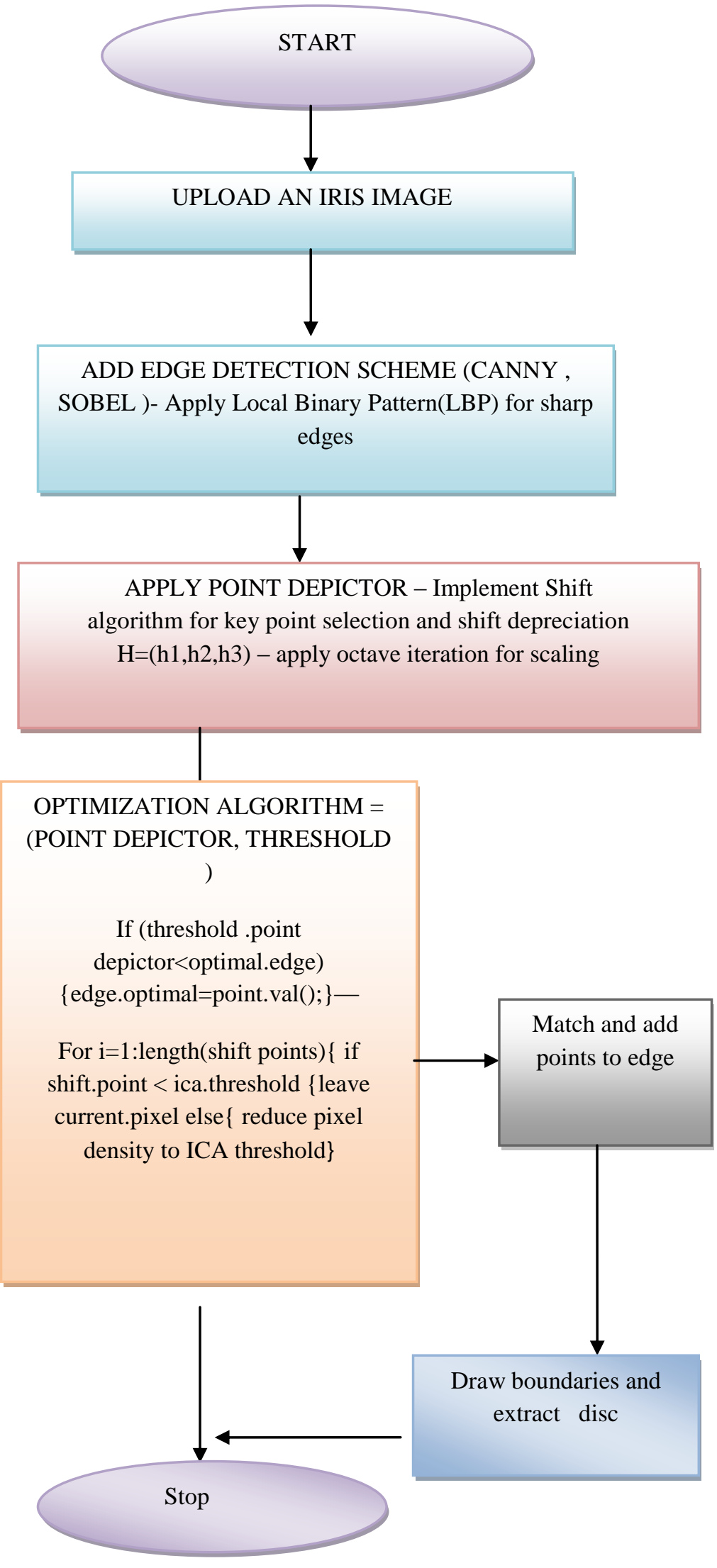


Table.1 Results value

\begin{tabular}{|c|c|c|c|}
\hline $\begin{array}{l}\text { DATA } \\
\text { BASE } \\
\text { TYPE }\end{array}$ & $\begin{array}{l}\text { ACCURACY } \\
\text {-HOUGH } \\
\text { TRANSFOR } \\
\text { MATION } \\
\text { CIRCULAR }\end{array}$ & $\begin{array}{l}\text { ACCURACY } \\
\text { HOUGH } \\
\text { CIRCULAR } \\
\text { TRANSFOR } \\
\text { MATION }\end{array}$ & $\begin{array}{l}\text { ICA+SIFT+H } \\
\text { OUGH } \\
\text { CIRCULAR } \\
\text { TRANSFOR } \\
\text { MATION }\end{array}$ \\
\hline CASIA & $75 \%$ & $81 \%$ & 93 \\
\hline
\end{tabular}

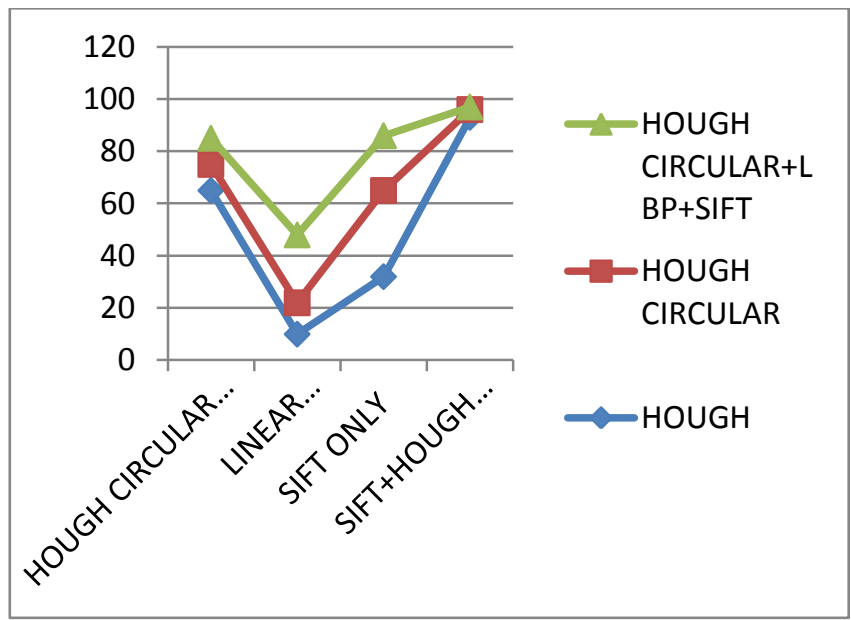

Figure.2 Chart represents the accuracy of method

\section{CONCLUSION}

Proposed technique that uses the concept of SIFT along with LBP and Hough Transformation works effectively, by locating the center of the disc accurately. As shown in the above figure, the system has recognized the proper dices. The drawback of the current system is that it does not work for the heavily noisy images as there is not a very sophisticated algorithm for the noise removal in this research work. The future research workers can try their hand on the noise removal techniques and the NEURAL network in this particular arena.

\section{REFERENCES}

[1] VV Kumari, N Suriyanarayanan, Blood vessel extraction using wiener filter and morphological operation. Int. J. Comput. Sci. Emerg. Technol. 1(4), 7-10 (2010)

[2] H Farzin, H Abrishami Moghaddam, M-S Moin, A novel retinal identification system. EURASIP J. Adv. Signal Process 2008, Article ID 280635 (2008). Publisher Full Text

[3] M Ortega, MG Penedo, J Rouco, N Barreira, MJ Carreira, Retinal verification using a feature points-based biometric pattern. EURASIP J. Adv. Signal Process 2009, Article $\quad$ ID 235746 (2009). Publisher Full Text

[4] Y Jiang, A Bainbridge-Smith, AB Morris, Blood vessel tracking in retinal images. Proceedings of Image and Vision Computing, 126-131 (2007)
[5] $\mathrm{R}$ Abdel-Ghafar, $\mathrm{T}$ Morris, $\mathrm{T}$ Ritchings, I Wood, Detection and characterisation of the optic disk in glaucoma and diabetic retinopathy. Proceedings of Medical Image Understanding and Analysis (2004)

[6] AA Youssif, AZ Ghalwash, AS Ghoneim, Comparative study of contrast enhancement and illumination equalization methods for retinal vasculature segmentation. Cairo International Biomedical Engineering Conference (CIBEC) (2006)

[7] AA Youssif, AZ Ghalwash, AS Ghoneim, A comparative evaluation of preprocessing methods for automatic detection of retinal anatomy. Proceedings of the Fifth International Conference on Informatics and Systems (INFOS 07), 24-30 (2007)

[8] A Osareh, in Automated identification of diabetic retinal exudates and the optic disc, ed. by . Ph.D. dissertation (Department of Computer Science, Faculty of Engineering, University of Bristol, Bristol, UK, 2004)

[9] AA Youssif, AZ Ghalwash, AS Ghoneim, Optic disc detection from normalized digital fundus images by means of a vessels' direction matched filter. IEEE Trans. Med. Imag. 27, 11-18 (2008)

[10] $\mathrm{H} \mathrm{Li}, \mathrm{O}$ Chutatape, Automatic location of optic disc in retinal images. Proceedings of the International Conference on Image Processing (ICIP), vol. 2, 837-840 (2001)

[11] RM Rangayyan, X Zhu, FJ Ayres, AL Ells, Detection of the optic nerve head in fundus images of the retina with Gabor filters and phase portrait analysis. J. Digit. Imag. 23(4), 438-453 (2010). Publisher Full Text

[12] X Zhu, RM Rangayyan, AL Ells, Detection of the optic nerve head in fundus images of the retina using the hough transform for circles. J. Digit. Imag. 23(3), 332341 (2010).Publisher Full Text

[13] A Aquino, ME Gegundez, D Mar, Automated optic disc detection in retinal images of patients with diabetic retinopathy and risk of macular edema. Int. J. Med. Med. Sci, 87-92 (2010)

[14] PC Siddalingaswamy, K Gopalakrishna Prabhu, Automatic localization and boundary detection of optic disc using implicit active contours. Int. J. Comput. Appl. 1, 7 (2010)

[15] M Foracchia, E Grisan, A Ruggeri, Detection of optic disc in retinal images by means of a geometrical model of vessel structure. IEEE Trans. Med. Imag. 23(10), 1189-1195 (2004).Publisher Full Text

[16] EJ Carmona, M Rincón, J García-Feijoo, JM Martínezde-la-Casa, Identification of the optic nerve head with genetic algorithms. Artif. Intell. Med. 43(3), 243-259 (2008).PubMed Abstract | Publisher Full Text

[17] KW Tobin, E Chaum, VP Govindasamy, TP Karnowski, Detection of anatomic structures in human retinal imagery. IEEE Trans. Med. Imag. 26(12), 1729-1739 (2007)

[18] M Niemeijer, MD Abramoff, BV Ginneken, Segmentation of the optic disc macula and vascular arch in fundus photographs. IEEE Trans. Med. Imag. 26(1), 116-127 (2007) 
[19] AD Fleming, KA Goatman, S Philip, JA Olson, PF Sharp, Automatic detection of retinal anatomy to assist diabetic retinopathy screening. Phys. Med. Biol. 52, 331345 (2007).PubMed Abstract | Publisher Full Text

[20] D Welfer, J Scharcanski, CM Kitamura, MM Dal Pizzol, LWB Ludwig, DR Marinho, Segmentation of the optic disk in color eye fundus images using an adaptive morphological approach. Comput. Biol. Med 40, 124 137 (2010). PubMed Abstract | Publisher Full Text

[21] M Niemeijer, B van Ginneken, F Ter Haar, MD Abramoff, Automatic detection of the optic disc, fovea and vascular arch in digital color photographs of the retina. Proceedings of the British Machine Vision Conference, 109-118 (2005)

[22] S Sekhar, W Al-Nuaimy, AK Nandi, Automatic localization of optic disc and fovea in retinal fundus. 16th European Signal Processing Conference (2008)

[23] M Park, JS Jin, S Luo, Locating the optic disk in retinal images. Proceedings of the International Conference on Computer Graphics, Imaging and Visualization, 141-145 (2006)
[24] F Ter Haar, in Automatic localization of the optic disc in digital color images of the human retina, ed. by . M.S. thesis (Utrecht University, Utrecht, The Netherlands, 2005)

[25] SF Barrett, E Naess, T Molvik, Employing the Hough transform to locate the optic disk. Biomed. Sci. Instrum. 37, 81-86 (2001). PubMed Abstract

[26] K Lee Lerner, BW Lerner, The Gale Ecyclopedia of Science, 3rd edn (Thomson-Gale, 2004), p. 1569

[27] A Osareh, B Shadgar, Automatic blood vessel segmentation in color images of retina. Iran. J. Sci. Technol. Trans. B: Engineering 33(B2), 191-206 (2009)

[28] J Staal, MD Abramoff, M Niemeijer, MA Viergever, B van Ginneken, Ridge-based vessel segmentation in color images of the retina. IEEE Trans. Med. Imag. 23, 501509 (2004).Publisher Full Text

[29] A Hoover, V Kouznetsova, M Goldbaum, Locating blood vessels in retinal images by piecewise threshold probing of a matched filter response. IEEE Trans. Med. Imag. 19(3), 203-210 (2000). Publisher Full Text 